\title{
Biological Responses of Lumbriculus variegatus Exposed to Fluoranthene-Spiked Sediment
}

\author{
P. F. Landrum, ${ }^{1}$ M. L. Gedeon, ${ }^{2}$ G. A. Burton, ${ }^{3}$ M. S. Greenberg, ${ }^{3}$ C. D. Rowland ${ }^{3}$ \\ 1 Great Lakes Environmental Research Laboratory, 2205 Commonwealth Blvd., Ann Arbor, Michigan 48105, USA \\ 2 Cooperative Institute for Limnology and Ecosystem Research, 2200 Bonisteel Ave., University of Michigan, Ann Arbor, Michigan 48109, USA \\ ${ }^{3}$ Institute for Environmental Quality, 3640 Colonel Glenn Hwy., Wright State University, Dayton, Ohio 45435, USA
}

Received: 31 May 2001/Accepted: 9 November 2001

\begin{abstract}
Lumbriculus variegatus was used as a bioassay organism to examine the impact of the sediment-associated polycyclic aromatic hydrocarbon (PAH) fluoranthene on behavior, reproduction, and toxicokinetics. The number of worms increased between the beginning and end of the experiment at $59 \mu \mathrm{g} \mathrm{g}^{-1}$ fluoranthene, but at the next higher treatment (108 $\mu \mathrm{g} \mathrm{g}^{-1}$ ) the number of worms found was lower and not different from the control. Worms exposed to $95 \mu \mathrm{g} \mathrm{g}^{-1}$ also exhibited increased reproduction when fed a yeast-cerophyltrout chow mixture. On a total biomass basis, only the $95 \mu \mathrm{g}$ $\mathrm{g}^{-1}$ exposure with food exhibited a statistically significant increase over the nonfed control. Evaluation of reproduction at the two highest treatments was compromised by a brief aeration failure 2 days before the end of the experiment. The behavioral responses were followed as changes in biological burial rate (sediment reworking rate) of a ${ }^{137} \mathrm{Cs}$-labeled marker layer. The biological burial rate increased toward a plateau as the concentration increased from the control $\left(3.9 \mu \mathrm{g} \mathrm{g}^{-1}\right.$ dry weight total PAH) to $355 \mu \mathrm{g} \mathrm{g}^{-1}$ dry weight fluoranthene in sediment. The aeration failure had minimal impact on the determination of reworking rate because all the data for the rate determination were collected prior to the aeration failure. Uptake and elimination rates declined with increasing treatment concentration across the range of fluoranthene concentrations, 59-355 $\mu \mathrm{g} \mathrm{g}^{-1}$ dry weight sediment. The disconnect between the increasing biological burial rates and the decreasing toxicokinetics rates with increasing exposure concentration demonstrates that the toxicokinetic processes are dominated by uptake and elimination to interstitial water. The bioaccumulation factor (concentration in the organisms on a wet weight basis divided by the concentration in sediment on a dry weight basis) ranged from 0.92 to 1.88 on day 10 and declined to a range of 0.52 to 0.99 on day 28 with the lowest value at the highest dose.
\end{abstract}

Sediment-associated contaminants can affect organisms at various concentrations, producing effects ranging from behavioral

Correspondence to: P. F. Landum; email: landrum@glerl.noaa.gov changes to mortality. Mortality was the dominant endpoint for many years during the development of sediment bioassays, but recent guidance calls for the addition of nonlethal endpoints, such as growth and reproduction (US EPA 2000; ASTM 2000).

Oligochaetes have an intimate contact with the sediment and have important roles in aquatic systems both as a prey item and for the bioturbation (mixing) of sediments by feeding at depth and depositing fecal materials at the surface (Fisher et al. 1980; Krezoski and Robbins 1985; Robbins 1986). Several species have been investigated for application in freshwater sediment bioassays (Bailey and Liu 1980; Keilty et al. 1988a, 1988b, 1988c; Reynoldson et al. 1991). Currently, the oligochaete Lumbriculus variegatus is the recommended organism for determining bioaccumulation of sediment-associated contaminants in fresh water (US EPA 2000; ASTM 2000) and has been used as a toxicity bioassay organism (Bailey and Liu 1980; Ankley et al. 1991; Kukkonen and Landrum 1994; Monson et al. 1995; Drews 1997).

Of the bioassays used for assessing effects on oligochaetes, sediment-reworking rates (determined as biological burial rates of a marker layer) have proven to be a sensitive indicator of oligochaete response to contaminant concentrations in sediments (Keilty et al. 1988b, 1988c; Keilty and Landrum 1990). The approach uses the conveyor-belt feeding activity of the oligochaete to bury a radiolabeled marker layer in sediment. For the control, changes in the burial rate are a function of feeding rate, the number and density of organisms, and the characteristics of the sediment. With exposure to contaminants, sediment reworking rate will also be affected by the impact of the contaminants on the worms. When sediment reworking rates were used for the assessment of endrin-contaminated sediment, a reduction of the biological burial rate of a marker layer was observed at endrin sediment concentrations approximately four to five orders of magnitude lower than those required to produce mortality at $96 \mathrm{~h}$ and about 10-fold lower than concentrations that affect growth (Keilty et al. 1988c). Sediment reworking rates have also proven useful for evaluating the impact of contaminants in field-collected samples (Keilty and Landrum 1990).

Recent work has suggested that the chemical body residue can be used as the dose to evaluate the toxicity of contaminants in aquatic organisms (McCarty and Mackay 1993). In L. var- 
iegatus, the toxicity of selected polychlorinated biphenyl congeners and DDE were examined using growth, mortality, and reproduction as endpoints (Fisher et al. 1999). Mortality was not a very sensitive endpoint for this species; significant mortality was observed in the range of $0.5-1.4 \mathrm{mmol} \mathrm{kg}{ }^{-1}$ after 35 days of exposure. Reductions in biomass and reproduction were found at lower concentrations, $0.3-0.6 \mathrm{mmol} \mathrm{kg}^{-1}$ (Fisher et al. 1999). Based on the apparent sensitivity of sediment reworking compared to growth from the endrin data mentioned here, it is likely that changes in the sediment reworking rate will occur at body residue concentrations lower than those that affect growth.

Because sediment reworking has proven to be a sensitive behavorial endpoint for toxicity response in other oligochaetes, the objectives of this study were to determine the sediment reworking rate of L. variegatus in response to sediments spiked with fluoranthene as a representative polycyclic aromatic hydrocarbon $(\mathrm{PAH})$ to establish the body residue concentrations required to produce changes in the reworking rate, and to measure the toxicokinetics to determine the exposure of the organisms relative to the reworking rate.

\section{Materials and Methods}

\section{Chemicals}

${ }^{14} \mathrm{C}$-Fluoranthene (specific activity $45 \mu \mathrm{Ci} / \mu \mathrm{mol}$ ) was purchased from Sigma Chemical (St. Louis, MO). Unlabeled fluoranthene was purchased form Aldrich Chemical (St. Louis, MO). The radiolabeled compound was examined for radiopurity prior to use by thin-layer chromatography (TLC) on silica gel plates using a solvent system of hexane:benzene 8:2. The compound was purified by TLC under these conditions. The region corresponding to the retention factor (RF) of the unlabeled standard was scraped from the plate and the compound eluted from the silica gel with acetone. The resulting material was found to have a radiopurity of $98 \%$. The unlabeled standard was used without purification.

\section{Organisms}

The oligochaete L. variegatus was obtained from the U.S. Environmental Protection Agency (U.S. EPA), Midcontinent Ecology Division (Duluth, MN). The worms were cultured in a 38 -L aquarium with a substrate of shredded, unbleached paper towel. The culture was maintained at room temperature under gold fluorescent light. The paper towel was presoaked in well water before being added to the aquarium. Approximately $5-8 \mathrm{~L}$ of well water was passed through the aquarium daily, and the aquarium was well aerated. The culture was fed twice a week with $3 \mathrm{~g}$ of ground trout chow.

\section{Sediments}

All experimental manipulations including the exposures were performed under yellow light with $\lambda>500 \mathrm{~nm}$ to reduce photodegradation. Sediments were collected from the Little Scioto River $(\mathrm{OH})$ at a site $\left(40^{\circ} 35.55^{\prime} \mathrm{N}\right.$ by $\left.83^{\circ} 10.98^{\prime} \mathrm{W}\right)$ with very low concentrations of PAHs $\left(3.9 \mu \mathrm{g} \mathrm{g}^{-1}\right)$. The sediment PAH concentration was determined at Wright State University using U.S. EPA method 8270 except that selected ion monitoring was used for the gas chromatography/mass spectrometry (GC/MS) method instead of full scan to maximize the sensitivity of the analysis. Sediments were press sieved through a 1-mm sieve to remove large debris and macrofauna. The sediment was then homogenized by mixing in large buckets using motorized mixers.

\section{Sediment Dosing}

Stock solutions were made by creating five dosing stocks from an original solution of $25 \mathrm{mg} \mathrm{ml}^{-1}$ fluoranthene. The original stock solution was prepared by dissolving $2.5 \mathrm{~g}$ unlabeled fluoranthene in $100 \mathrm{ml}$ acetone in a volumetric flask. The dosing solutions were made by adding the appropriate amount of unlabeled compound and 13.6 $\mu \mathrm{Ci}(61 \mu \mathrm{g})$ of labeled fluoranthene to create nominal concentrations of 50,100,200, and $300 \mu \mathrm{g} \mathrm{g}^{-1}$ dry sediment. Two batches of $100 \mu \mathrm{g}$ $\mathrm{g}^{-1}$ were prepared to provide two treatments, one in which the worms would be fed YCT (yeast, cerophyl, trout chow recipe yields 1.7-1.9 $\mathrm{g} \mathrm{L}^{-1}$; US EPA 1993) and one where the worms would not be fed. The new specific activities of the stock solutions were determined by liquid scintillation counting and UV/VIS spectrometry. The spectrophotometric analyses of the stocks were determined on a Perkin Elmer Lambda $6 \mathrm{UV} / \mathrm{Vis}$ Spectrophotometer at $360 \mathrm{~nm}$. The fluoranthene stock concentrations were compared to a standard curve after appropriate dilution.

Sediments were spiked using a modification of the rolling jar method according to Ditsworth et al. (1990). The stock solutions (25 $\mathrm{ml}$ ) were added to gallon jars containing $5 \mathrm{~g}$ of sand and rolled until the acetone carrier was evaporated, coating the sand and jars with fluoranthene. The control was prepared in the same way using acetone without fluoranthene. Sediment (3,000 g wet weight) was added to each jar for each treatment, including the controls. The jars were capped with Teflon-lined lids and rolled for $8 \mathrm{~h}$ at room temperature. The jars were left at $4^{\circ} \mathrm{C}$ overnight and rolled the next day for an additional $4 \mathrm{~h}$. The sediments (Table 1) were then held to equilibrate for a total of 33 days. After 1 week of equilibration, total sediment radioactivity was determined on sediment samples $(\sim 100 \mathrm{mg}$ wet weight) taken from each jar, placed in scintillation cocktail (3a70B, RPI International), sonicated for 60 s (Tekmar Model TM375 Sonic Disruptor), and then allowed to stand overnight prior to counting. The samples were counted for $10 \mathrm{~min}$ on a Packard Tri Carb model TR2500 scintillation counter. The samples were corrected for quench using the external standards ratio method after subtracting background. The variation in sample concentration at each treatment concentration was $>10 \%$ at this time; therefore, the sediments were rolled for an additional $4 \mathrm{~h}$. The sediments were returned to $4^{\circ} \mathrm{C}$ to complete the equilibration. The equilibration of the contaminant with the interstitial water was followed over time by removing sediment samples (15-30 g) at approximately 1-week intervals from the highest treatment and centrifuging at 5,500 $\mathrm{g}$ for $20 \mathrm{~min}$. The supernatant (interstitial water) was sampled $(2 \mathrm{ml})$, placed in scintillation cocktail and the amount of activity determined. The activity in the interstitial water appeared to reach steady state after about 3 weeks.

The organic carbon content of the sediments was determined initially and at the end of the experiment. The sediment samples $(0.5-1$ g wet weight) were treated with $1 \mathrm{~N} \mathrm{HCl}(2 \mathrm{ml})$ and agitated for $24 \mathrm{~h}$ to remove carbonates and subsequently dried. A subsample was taken, weighed, and organic carbon determined on a CE Instruments EA $1110 \mathrm{CHN}$ analyzer (ThermoQuest Italia, Milan, Italy).

The distribution of the fluoranthene among the various particle sizes was determined by wet sieving a $15-\mathrm{g}$ wet sample though a series of sieves $(106,63,37$, and $20 \mu \mathrm{m})$. The sample was gently wet sieved using $1 \mathrm{~L}$ Huron River water, and the residue in each sieve was transferred to tared aluminum pans for drying. The samples were dried at $70^{\circ} \mathrm{C}$ to constant weight. The dry sample was transferred to a scintillation vial and sonicated in scintillation cocktail for $2 \mathrm{~min}$. The ${ }^{14} \mathrm{C}$ activity was determined by LSC as described. The mass account- 
Table 1. Accumulated dose of fluoranthene by Lumbriculus variegatus after 10-day and 28-day exposures

\begin{tabular}{lllll}
\hline $\begin{array}{l}\text { Sediment } \\
\begin{array}{l}\text { Concentration } \\
\left(\mu \mathrm{g} \mathrm{g}^{-1}\right)\end{array}\end{array}$ & $\begin{array}{l}\text { 10-day } \\
\text { Accumulation } \\
\left.(\mathrm{mmol} \mathrm{kg})^{-1}\right)\end{array}$ & $\begin{array}{l}\text { 28-day } \\
\text { Accumulation } \\
\left(\mathrm{mmol} \mathrm{kg}^{-1}\right)\end{array}$ & $\begin{array}{l}\text { No. Worms } \\
\text { At 28 Days }\end{array}$ & $\begin{array}{l}\text { Total Mass } \\
\text { Worms per } \\
\text { Cell }(\mathrm{mg})\end{array}$ \\
\hline 59 & $0.27 \pm 0.03$ & $0.19 \pm 0.02$ & $92 \pm 2$ & $307 \pm 42$ \\
108 & $1.01 \pm 0.05$ & $0.53 \pm 0.19$ & $80 \pm 1$ & $276 \pm 4$ \\
$95^{\mathrm{a}}$ & $0.69 \pm 0.16$ & $0.46 \pm 0.07$ & $97 \pm 9$ & $61 \pm 14^{\mathrm{c}}$ \\
252 & $1.78 \pm 0.09$ & $0.65 \pm 0.15$ & $54 \pm 10^{\mathrm{c}}$ & $279^{\mathrm{d}}$ \\
355 & $3.10 \pm 0.25$ & $1.01 \pm 0.16$ & $77 \pm 4$ & $263^{\mathrm{d}}$ \\
Control & $\mathrm{NA}$ & $\mathrm{NA}$ & $276 \pm 36$ \\
\hline
\end{tabular}

${ }^{a}$ Fed YCT twice weekly.

${ }^{\mathrm{b}}$ Average concentrations for worms in kinetics and gamma scan exposures.

${ }^{c}$ Aeration failed on day 26 in aquarium containing the cells for this treatment.

${ }^{\mathrm{d}}$ Mass based on $90 \%$ survival due to aeration failure. NA $=$ Not applicable.

ability was $100 \pm 17 \%$ (mean $\pm \mathrm{SD}$, one outlier had recovery of $66 \%$, otherwise the recovery was $107 \pm 0.6 \%$ ), and radioactivity recovery was $70 \pm 14 \%$.

\section{Toxicokinetic Determination}

The toxicokinetics of fluoranthene in L. variegatus were determined by measuring the fluoranthene concentration in the worms after $1,2,5$, 10,14 , and 28 days of exposure. Duplicate beakers $(200 \mathrm{ml})$ for each time point and each treatment were filled with $100 \mathrm{~g}$ wet sediment per beaker and $100 \mathrm{ml}$ of filtered Huron River water. The beakers were immersed in temperature-controlled aquaria at $23^{\circ} \mathrm{C}$ and allowed to stand for $48 \mathrm{~h}$ prior to organism addition (10 worms per beaker). Half of the overlying water in the beakers was replaced daily. There were two treatments at about $100 \mu \mathrm{g} \mathrm{g}^{-1}$ fluoranthene, one with food (YCT) and one without. The food ration for each beaker was initially $3 \mathrm{ml}$ twice a week (this amount was based on ingestion rate of $4 \%$ of the biomass per day). However, it became evident after the first addition that this ration was too large, because the equivalent amount used in the reworking study cells created a temporary hypoxic condition during feeding that caused the worms to tend to exit the sediment. Thus the ration was reduced to $2 \%$ of biomass, reducing the volume to $1.5 \mathrm{ml}$ twice a week. Thus the equivalent ration for each of the treatment cells where the worms were fed would be $12 \mathrm{ml}$ YCT twice a week.

The beakers were sampled destructively on the above sampling schedule to collect data on numbers of worms and fluoranthene concentrations in the worms. The sediments were analyzed for fluoranthene concentration at the beginning of the study, on day 14, and on day 28. Sediment samples were analyzed for fluoranthene as described above, and a second sample was taken for determining the dry to wet weight ratio. The sediments for dry to wet weight were weighed, dried at $70^{\circ} \mathrm{C}$, and reweighed. The worms were recovered from the sediment by gently wet-sieving the sediment through a $355-\mu \mathrm{m}$ sieve. The worms were rinsed into a pan and separated from the residual sediment and placed into petri dishes containing Huron River water to evacuate their guts for $6 \mathrm{~h}$ as recently recommended (Mount et al. 1999). The worms were then blotted dry, weighed, and placed in scintillation cocktail as specified. The organisms were shaken with the cocktail and allowed to stand for $24 \mathrm{~h}$ prior to counting. The scintillation cocktail serves as the extracting solvent for the contaminants. Organisms placed in scintillation cocktail but sonicated to disrupt the organism gave essentially identical results to unsonicated organisms (unpublished data).

In addition, the lipid content of worms was determined on day 0 from the culture and on the last day of the kinetics study, day 28. The worms were allowed to purge their guts as above, blotted dry, placed in small, tared plastic weighing boats, and dried in a desiccator under a nitrogen atmosphere. Once dry, the worms were weighed and transferred to $16 \times 100 \mathrm{~mm}$ glass culture tubes. The lipid content was determined by the spectrophotometric procedure of Van Handel (1985). Briefly, the lipids were extracted twice with $0.5 \mathrm{ml}$ chloroform: methanol (1:1), the extract was reduced to dryness on a heat block at $100^{\circ} \mathrm{C}$, and $0.2 \mathrm{ml}$ of $95-98 \%$ sulfuric acid was added and the samples heated for an additional $10 \mathrm{~min}$. Subsequently, a vanillin-phosphoric acid reagent $(5 \mathrm{ml})$ was added, and the color was allowed to develop for $5 \mathrm{~min}$. The samples were read on a spectrophotometer at $525 \mathrm{~nm}$. Soybean oil was used to develop the standard curve by creating solutions of 5-300 $\mu \mathrm{g}$. This method was compared with a microgravimetric method (Gardner et al. 1985) for an aquatic algae used in our laboratory as a standard matrix and yielded $29.03 \pm 3.9 \%$ lipid on a dry weight basis by the spectrophotometric method and $31.56 \pm$ $4.9 \%$ lipid by the micro-gravimetric method.

\section{Contaminant Degradation and Biotransformation}

The degradation of the fluoranthene was determined at the end of the experiment in both the sediment and the worms. The day 28 sediment samples were kept frozen at $-20^{\circ} \mathrm{C}$ until analysis ( $\sim 40$ days). The sediments were thawed, desiccated with anhydrous sodium sulfate, placed in 250-ml Erlenmeyer flasks, covered with aluminum foil, and extracted with dichloromethane $(120 \mathrm{ml})$ by sonication for $1 \mathrm{~h}$ at $30^{\circ} \mathrm{C}$ in a Branson 8210 sonicator bath (Branson Ultrasonics, Dansbury, $\mathrm{CT}$ ), allowed to stand for $24 \mathrm{~h}$, and then sonicated for an additional hour. The solvent was removed, reduced in volume on a TurboVap ${ }^{\mathrm{TM}}$ (Zymark, Hopkinton, MA) to $0.5 \mathrm{ml}$. A portion of the resulting solution was spotted on a TLC plate and developed in hexane:benzene (80:20). The silica gel was scraped from the TLC plate in 11 sections $(1 \mathrm{~cm})$ and placed in scintillation cocktail. The silica gel was counted for radioactivity, and the percent parent compound was calculated as the amount of activity corresponding to the RF of a standard divided by the total activity of all the sections. The amount of degradation is the difference from $100 \%$.

The worms were weighed and frozen at $-20^{\circ} \mathrm{C}$ until analysis $(\approx 40$ days). The tissues were placed in a manual tissue grinder and ground twice with $12 \mathrm{ml}$ ethylacetate:acetone (4:1) and the solvent decanted into a funnel containing anhydrous sodium sulfate. This was repeated twice more with $12 \mathrm{ml}$ cyclohexane. The solvents were combined and the volume reduced and analyzed as above. 


\section{Reworking Study}

Triplicate glass cells $(3 \mathrm{~cm} \times 5 \mathrm{~cm} \times 30 \mathrm{~cm})$ for each treatment $(19$ cells in total) were filled with $450 \mathrm{~g}$ wet sediment. This filled the cells to approximately two-thirds of their height. Huron River (MI) water was added gently to fill the cells, and they were immersed in temperature-controlled $\left(23 \pm 1^{\circ} \mathrm{C}\right)$ aquaria. The water level in the aquaria was about $5 \mathrm{~cm}$ above the top of the cells, and the aquaria were aerated. The controls consisted of cells with no worms to account for compaction during the course of the experiment and with worms for control reworking rates. The controls were only run in duplicate because of limited space in the aquaria. The cells were spiked with a thin layer of ${ }^{137} \mathrm{Cs}$ (approximately $1 \mu \mathrm{Ci}$ per cell) sorbed to illite clay and allowed to settle for 2 days. The cells were then scanned for initial gamma activity; then, 75 worms were added per cell (except for the two control cells for compaction). This is a density equivalent to 50,000 worms per $\mathrm{m}^{2}$. This density is similar to that used previously for reworking rate studies (Kietly et al. 1988a, 1988b) and is far less than maximal densities of oligochaetes observed in freshwater environments of $10^{6}$ per $\mathrm{m}^{2}$ (McCall and Tevesz 1982). The cells were scanned every 2 days for the duration of the experiment. The $95 \mu \mathrm{g}$ $\mathrm{g}^{-1}$ fluoranthene treatment was fed at $24 \mathrm{ml}$ YCT per cell twice a week, and the food ration was reduced to $12 \mathrm{ml} \mathrm{YCT}$ after the first application as described above.

The gamma activity and position of the ${ }^{137} \mathrm{Cs}$ marker layer were determined in each microcosm using a gamma scan system. The basic system has been previously described (Robbins et al. 1979). For these experiments, an upgraded automated system was used (Keilty and Landrum 1990). It consisted of a well-collimated sodium iodide detector supported on a mechanically driven elevator/platform capable of precise, repeatable movements $(0.1 \mathrm{~mm}$ accuracy and repeatability) in both $\mathrm{x}$ - and $\mathrm{y}$-axes. The apparatus was used to vertically scan the experimental microcosms.

At the end of the experiment, the overlying water was removed and one side of each cell was removed. The sediment containing the worms, the top 5-7 cm, was removed, and the organisms were recovered as described above for the kinetics studies. The number of worms, the concentration of fluoranthene in the worms and sediments, and the lipid content of the worms were determined as in the kinetic experiments.

\section{Interpretation of Gamma Scan Profiles}

Because the detector system is well collimated, a scan of a thin layer of gamma-emitting material produces a net counting rate profile, which has a Gaussian functional form (Robbins et al. 1979):

$$
R(z)=R\left(z_{\max }\right) e^{-\left(z-z_{\max }\right)^{2} / 2 \sigma_{o b s}^{2}} .
$$

Thus, each profile can be described by three parameters: (1) the depth of the maximum counting rate $\left(z_{\max }\right)$ in $\mathrm{cm}$; (2) the width or spread in the profile $\left(\sigma_{o b s}\right)$ in $\mathrm{cm}$; and (3) the maximum counting rate $\left(R_{\max }\right)$. Independent least-squares fit of a Gaussian function to cell profiles provides an acceptable representation of the data.

The observed spread $\left(\sigma_{o b s}\right)$ is due to a combination of the actual spread in the distribution of tracer in the microcosm $(\sigma)$ and the optics of the detector system $\left(\sigma_{o}\right)$. This latter value $(0.04 \mathrm{~cm})$ was determined by scanning an extremely thin layer of tracer embedded in a plastic medium. A correction for detector optics is obtained using the semiempirical relation

$$
\sigma^{2}=\sigma_{o b s}^{2}-\sigma_{o}^{2}
$$

The three Gaussian parameters may be related to interactions of organisms with sediments. Layers of radiolabeled sediment in exper- imental microcosms are altered by feeding and locomotory activities of introduced infaunal benthos. First, thin labeled layers will spread vertically as organisms mix sediments. This process has often been successfully treated being small-scale diffusive in character (Boudreau 1986) and measured in terms of a bulk sediment mixing coefficient, $D_{b}$. It can be shown (Crank 1975) that $\sigma^{2}=D_{b} t$, where $t$ is the time elapsed since start of the experiment. Hence, in this study, $D_{b}$ is obtained as the slope of $\sigma^{2}$ versus time. Second, infaunal feeding will remove radio-labeled sediments from initial layers and distribute them to other parts of microcosms, particularly to the surface for head-down feeders. Though the absolute amount of tracer is not easily determined by the scanning method, it is proportional to the product $\sigma R_{\max }$. For the present study, because there was only one layer and feeding generally occurred below the level of the marker layer, no feeding activity could be determined. Third, in the case of head-down deposit feeders such as $L$. variegatus, which feed well below the sedimentwater interface under natural conditions, a marked layer at depth $z$ above their zone of feeding will be displaced downward as ingested sediments are removed and redeposited at the surface. The rate of layer burial is measured as $W_{b}=\mathrm{d} z_{\max } / \mathrm{d} t$ (Krezoski and Robbins 1985; Robbins 1986). Thus the effects of fluoranthene on bulk sediment feeding can be measured by $W_{b}$.

\section{Kinetics Analysis}

Because the concentration in the worms declined in the last two time points while the sediment concentration remained essentially constant, the kinetics data were fit by nonlinear least squares regression to the following model (Landrum 1989):

$$
C_{a}(t)=\frac{k_{s} C_{s}}{k_{e}-\lambda}\left(e^{-\lambda t}-e^{-k_{e} t}\right),
$$

where $C_{a}$ is the concentration in the organism $\left(\mu \mathrm{g} \mathrm{g}^{-1}\right), k_{s}$ is the uptake rate coefficient ( $\mathrm{g}$ dry sediment $\mathrm{g}^{-1}$ organism $\mathrm{h}^{-1}$ ), $C_{s}$ is the concentration in the sediment ( $\mu \mathrm{g} \mathrm{g}^{-1}$ dry weight sediment), $k_{e}$ is the elimination rate constant $\left(\mathrm{h}^{-1}\right), \lambda$ is the rate constant for loss of bioavailability, and $t$ is time (h).

\section{Statistics}

Linear and nonlinear regressions were performed with Scientist ${ }^{\circledR}$, Version 2.01 (MicroMath Scientific Software, Salt Lake City, UT) or Systat ${ }^{\circledR} 8.0$ (SPSS, Chicago, IL). Comparisons of slopes, intercepts, and means used a Student $t$ test. All values were considered significant at $\mathrm{p}<0.05$.

\section{Results}

\section{Sediments}

The initial dosing stock was $98.3 \pm 0.5 \%(\mathrm{n}=4)$ pure. The concentration of fluoranthene in the sediment did not change over the course of the study and was determined to be $97 \pm 1 \%$ $(n=10)$ fluoranthene at the end of 28 days. Thus the radioactivity is expected to represent essentially parent fluoranthene. The resultant mean sediment concentrations were $59 \pm 9(\mathrm{n}=$ 13), $108 \pm 10(\mathrm{n}=13), 95 \pm 22(\mathrm{n}=13$, with food $), 252 \pm$ $34(\mathrm{n}=9)$, and $355 \pm 67(\mathrm{n}=13) \mu \mathrm{g} \mathrm{g}^{-1}$ dry sediment for the various treatments. The average coefficient of variation for 
the measured fluoranthene concentration in sediment was $16 \pm$ $5 \%$. The organic carbon did not change over the course of the experiment $2.02 \pm 0.25 \%(\mathrm{n}=28)$ at day 0 versus $1.9 \pm$ $0.23 \%(\mathrm{n}=45)$ at day 28 .

\section{Reproduction and Growth}

Reproduction of the worms over the course of the experiment was evaluated by counting the number of worms in the reworking cells at the end of the experiment (Table 1). The number of worms in the control $(77 \pm 4, n=3)$ was essentially the same as the number added per cell (75). At $59 \mu \mathrm{g} \mathrm{g}^{-1}$, the number of worms increased significantly to $92 \pm 2$ worms per cell. At the next higher treatment $\left(108 \mu \mathrm{g} \mathrm{g}^{-1}\right)$, the number of worms was not significantly different from the control but was significantly lower than at the $59 \mu \mathrm{g} \mathrm{g}^{-1}$ treatment. At $95 \mu \mathrm{g} \mathrm{g}^{-1}$ with YCT feeding, the number of worms was similar to the 59 $\mu \mathrm{g} \mathrm{g}^{-1}$ treatment and significantly greater than for the $108 \mu \mathrm{g}$ $\mathrm{g}^{-1}$ treatment. Thus, the addition of food produced a favorable environment for reproduction despite the higher fluoranthene concentration. Because there was no control without fluoranthene and with a food ration, it is not possible to determine whether the fluoranthene had a detrimental effect even in the presence of food. At the two highest fluoranthene concentrations, the potential impact on reproduction could not be determined because the aeration failed on day 26 and a portion of the worms left the cells. This aeration failure lasted for less than $24 \mathrm{~h}$, as the cell conditions are monitored on at least a daily basis. In kinetics beakers, which were not subject to the aeration failure, there were only 10 organisms per replicate, an average of $9 \pm 0.8(n=4)$ worms were found at each concentration for the 252 and $355 \mu \mathrm{g} \mathrm{g}^{-1}$ treatments. Although 9 worms per beaker was not statistically lower than 10 , there were fewer than 10 worms in all but one replicate, suggesting that fluoranthene may be having some negative effect at these doses.

The biomass was calculated for each cell (Table 1). The only case where the biomass was significantly different from the control was in the $95 \mu \mathrm{g} \mathrm{g}^{-1}$ treatment where the worms were fed. In all other treatments, the total biomass was not significantly different from the control, assuming that the 252 and $355 \mu \mathrm{g} \mathrm{g}^{-1}$ concentrations had $90 \%$ survival. Thus from a biomass perspective, fluoranthene did not alter the growth of the organisms; however, feeding with YCT increased the growth over both the $108 \mu \mathrm{g} \mathrm{g}^{-1}$ treatment and the control.

The highest fluoranthene concentrations occurred after 10 days of exposure and tended to decline by 28 days (Table 1). The concentrations in the worms at the higher treatments was not adversely affected by the short-term oxygen reduction. The tissue concentration found from the kinetics exposures were $219 \pm 20$ and $106 \pm 27 \mu \mathrm{g} \mathrm{g}^{-1}$ in the worms for the 355 and $252 \mu \mathrm{g} \mathrm{g}^{-1}$ exposures, and from the cells the concentrations were $223 \pm 78$ and $131 \pm 25 \mu \mathrm{g} \mathrm{g}^{-1}$ in the worms, respectively, at day 28. At the higher exposures, the worms after 10 days of exposure had concentrations where $50 \%$ mortality by narcosis $\left(2-8 \mathrm{mmol} \mathrm{kg}^{-1}\right)$ has been observed in some organisms (McCarty and Mackay 1993) but dropped below that level by 28 days. However, the 28 -days concentrations were in the range where significant reductions in survival have been ob- served after 35 days in L. variegatus exposed to DDE or PCB congeners (0.88-1.35 mmol kg-1; Fisher et al. 1999). The treatment concentrations, except for the $59 \mu \mathrm{g} \mathrm{g}^{-1}$, resulted in tissue residues that were in the range that produced reductions in biomass or reproduction when $L$. variegatus were exposed to DDE or PCB congeners $\left(0.34 \mathrm{mmol} \mathrm{kg}^{-1}\right.$ or greater; Fisher et al. 1999). However, no reductions in reproduction were observed for the 95 and $108 \mu \mathrm{g} \mathrm{g}^{-1}$ treatments, and the biomass was essentially constant among the treatments assuming the $90 \%$ survival for higher doses.

\section{Reworking Rate}

The ${ }^{137}$ Cs-marker layer can exhibit both diffusive mixing $\left(D_{b}\right)$ and burial $\left(W_{b}\right)$. Diffusive mixing is peak broadening from the worms moving through the sediment and feeding near the surface, causing the particles containing the ${ }^{137} \mathrm{Cs}$ to mix with the sediment particles. Biological burial of the marker layer results from the conveyor belt action of the worms feeding at depth and depositing material on the surface. The brief period of low oxygen due to the aeration failure as described above would have had little impact on the data collected for the reworking portion of the experiment because all the data used for the calculation of reworking rate had been collected prior to the aeration failure. The main impact in describing the rate processes is number and mass of worms attributable to the two highest treatments. Because the kinetics experiments were in independent containers and did not suffer from aeration problems, the average percent recovery from the kinetics beakers was used to establish the number of worms expected in the two highest treatments for the reworking study. This was thought to be conservative, as only a few worms left the cells during the short low oxygen condition. Thus $90 \%$ is likely a slight overestimate of the number of worms at 28 days.

$D_{b}$ was most pronounced in the 252 and $355 \mu \mathrm{g} \mathrm{g}^{-1}$ treatments and when the worms were exposed to $95 \mu \mathrm{g} \mathrm{g}^{-1}$ with feeding (Table 2). $\mathrm{D}_{\mathrm{b}}$ more than doubled compared to the control at $252 \mu \mathrm{g} \mathrm{g}^{-1}$ and increased by a factor of five at 355 $\mu \mathrm{g} \mathrm{g}^{-1}$. This enhanced diffusive activity was likely augmented by the organisms feeding near the surface of the sediment. This near-surface feeding was confirmed by the appearance of a second peak in the Cs activity appearing at the sediment-water interface about halfway through the reworking study at these higher treatments.

The greatest rate of diffusion was found for the organisms that were fed YCT. The peak broadened significantly within the first 2 days but did not broaden further during the study. No second peak of Cs activity was observed in this case, suggesting that the worms fed at or very near the surface. Thus the worms appeared to act more as diffusive mixers than conveyerbelt feeders when fresh food was added.

The ${ }^{137} \mathrm{Cs}$-marker layer dropped rapidly during the first 2 days then exhibited a generally linear decline through 400-450 h. After about 400-450 h (depending on the cell) the marker layer stopped moving. The control with no worms also showed additional settling during the first 2 days and then exhibited a very slow decline over the course of the remainder of the experiment. Thus, the reworking rate, the rate of burial $\left(W_{b}\right)$ of the $\mathrm{Cs}$ peak from the conveyor belt action of the worms feeding 
Table 2. Impact of sediment reworking by Lumbriculus variegatus in the presence of fluoranthene

\begin{tabular}{lll}
\hline $\begin{array}{l}\text { Sediment } \\
\begin{array}{l}\text { Concentration } \\
\left(\mu \mathrm{g} \mathrm{g}^{-1}\right)\end{array}\end{array}$ & $\begin{array}{l}\text { Biological } \\
\text { Diffusion Rate }\left(D_{b}\right)\end{array}$ & $\begin{array}{l}\text { Biological Burial Rate } \\
\left(W_{b}\right)\left(\mathrm{cm} \mathrm{g}^{-1} \mathrm{~h}^{-1}\right)\end{array}$ \\
\hline Control & $0.0002 \pm 0.0001$ & $3.47( \pm 0.42) \times 10^{-4}$ \\
59 & $0.0003 \pm 0.0000$ & $1.32( \pm 0.65) \times 10^{-3}$ \\
108 & $0.0003 \pm 0.0001$ & $5.78( \pm 0.74) \times 10^{-3}$ \\
$95^{\mathrm{a}}$ & $0.0012 \pm 0.0003^{\mathrm{b}}$ & $1.69( \pm 0.85) \times 10^{-3}$ \\
$252^{\mathrm{c}}$ & $0.0005 \pm 0.0002$ & $7.19( \pm 0.73) \times 10^{-3}$ \\
$355^{\mathrm{c}}$ & $0.0011 \pm 0.0003$ & $9.47( \pm 2.4) \times 10^{-3}$
\end{tabular}

${ }^{\mathrm{a}}$ Fed YCT twice weekly.

${ }^{\mathrm{b}}$ Estimated from first three scans of the peak.

${ }^{\mathrm{c}}$ Rates assume final worm mass based on $90 \%$ survival due to aeration failure.

at depth, was calculated for the linear portion of the data from $60-450 \mathrm{~h}$ for each cell. The slope of the settling control is subtracted from the calculated slope with the worms to give the net slope for each cell. The net slope for each cell is divided by the mass of worms found in the cell at the end of 28 days to give the reworking rate (biological burial rate, $W_{b}$ ). The biological burial rate exhibited a significant increase with increasing concentration of fluoranthene in sediments (Table 2, Figure 1). This suggests that the feeding rate of the worms, which is responsible for the Cs-layer burial, increased with increasing fluoranthene concentration. In the case of the worms fed YCT, the burial rate, though higher than the control, was about three times lower than for worms exposed at a similar treatment concentration that were not fed YCT (Table 2).

\section{Kinetics and Bioaccumulation}

Because the compound apparently did not degrade and the concentration in the sediments was essentially constant, the average sediment concentration was used for determining the kinetics. In addition, the fluoranthene in the worms was $91 \pm$ $3 \%(\mathrm{n}=6)$ parent compound. Thus biotransformation was not substantial and was not modeled. The kinetics were modeled as fluoranthene equivalents. Growth can be a confounding factor in the kinetics. For these studies, there were no significant changes in the number of worms found in the kinetics samples regardless of treatment, and the worm weight was generally constant except for the control, 59, and $108 \mu \mathrm{g} \mathrm{g}^{-1}$ treatments. In those treatments, the worms gradually lost weight over the course of 28 days by $26.9 \%, 32.4 \%$, and $23.5 \%$, respectively. Because the loss is gradual and the rate of loss is substantially slower than the elimination kinetics (Table 3), the loss of weight should not affect the kinetic determination and modeling. Another feature of the kinetics data was a general decline in worm concentration for the data after 10 days (Figure 2). This shape of kinetic curves has previously been modeled as a change in bioavailability (Landrum 1989; Harkey et al. 1995; Van Hoof et al. 2001). Modeling the data with this model resulted in acceptable fits to the data with the coefficient of determination in the range of $0.93-0.49$. The change in concentration in the worms over time has also been attributed to the loss of lipid in the organisms over the course of the

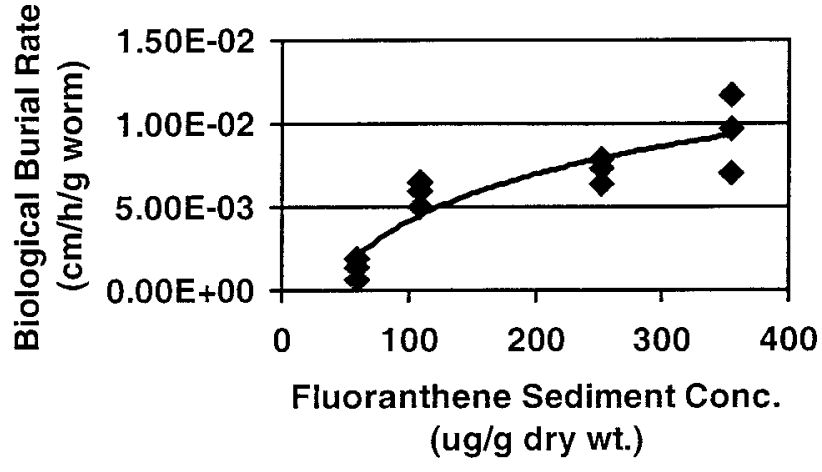

Fig. 1. The biological burial rate $\left(W_{b}\right)$ as a function of the fluoranthene sediment exposure concentration

exposure. After lipid normalization, no such decline was observed (Kukkonen and Landrum 1994). In this study, the lipid content of the worms did not decline as previously observed $(12.2 \pm 1.8 \%$ of dry weight at day 0 and $19.7 \pm 5.7 \%$ for day 28). Thus, normalizing to lipid content would not have improved the data. The sediments had been equilibrated for 33 days and the pore water came to apparent steady state after 3 weeks equilibration based on the pore water data from the highest treatment: week 1, 22.6 $\pm 5 \mathrm{DPM} \mathrm{ml}^{-1}$; week 2, 13.8 (13.2-14.2) $\mathrm{DPM} \mathrm{ml}{ }^{-1}$; and week 3, $12 \pm 1.7 \mathrm{DPM} \mathrm{ml}^{-1}$. Thus the sediments were likely near equilibrium with the particles when the exposure was initiated.

The uptake clearance obtained from the toxicokinetic model with declining bioavailability reflects both the accumulation from interstitial water and from ingestion of contaminated particles and declined with increasing fluoranthene concentration (Table 1, Figure 3). Though the accumulation is thought to proceed primarily through desorption from sediment particles and uptake from interstitial water (see following discussion), the decline may also be driven in part by changes in the distribution of the fluoranthene among sediment particles. At the higher treatment concentrations, the fluoranthene tended to be distributed toward the larger particles (Figure 4). L. variegatus is limited in the size of particles that it can feed on by the size of its mouth. L. variegatus has been reported to ingest particles in the 40-60 $\mu \mathrm{m}$ diameter range but not particles above $100 \mu \mathrm{m}$ diameter (Lawrence et al. 2000). Thus, even if the feeding rate was the same at each treatment, the exposure through ingestion would be different if the compound had differential distribution among sediment particles. Furthermore, such changes in distribution might also affect desorption rate, although such measurements have not been made to date.

In addition to the declining uptake with increasing fluoranthene sediment concentrations, the elimination rate also declined with increasing concentration (Table 3). In the two treatments where reproduction was the greatest, 59 and $95 \mu \mathrm{g}$ $\mathrm{g}^{-1}$, the elimination rate constants were also the largest. Previous studies exposing $L$. variegatus to pyrene showed that elimination continued while uptake was limited during reproduction (Leppänen and Kukkonen 1998). Thus reproduction may have contributed to the increased elimination, although the elimination at the $95 \mathrm{ug} \mathrm{g}^{-1}$ treatment is complicated by the additional food provided. 
Table 3. Toxicokinetics of fluoranthene in Lumbriculus variegatus

\begin{tabular}{|c|c|c|c|c|c|c|}
\hline $\begin{array}{l}\text { Sediment } \\
\text { Concentration } \\
\left(\mu g^{-1}\right)\end{array}$ & $k_{s}\left(\mathrm{~g}\right.$ sed. $\left.\mathrm{g}^{-1}\right)$ & $k_{e}\left(\mathrm{~h}^{-1}\right)$ & $\lambda\left(\mathrm{h}^{-1}\right)$ & $\mathrm{BAF}\left(k_{s} / k_{e}\right)$ & $\begin{array}{l}\text { BAF } 10 \\
\text { Days }\end{array}$ & $\begin{array}{l}\text { BAF } 28 \\
\text { Days }\end{array}$ \\
\hline 59 & $0.067 \pm 0.013$ & $0.074 \pm 0.016$ & $0.0008 \pm 0.0002$ & 1.0 & 0.92 & 0.65 \\
\hline 108 & $0.039 \pm 0.004$ & $0.020 \pm 0.002$ & $0.0027 \pm 0.0007$ & 3.18 & 1.88 & 0.99 \\
\hline $95^{\mathrm{a}}$ & $0.047 \pm 0.007$ & $0.033 \pm 0.006$ & $0.001 \pm 0.0003$ & 1.64 & 1.46 & 0.97 \\
\hline 252 & $0.029 \pm 0.003$ & $0.019 \pm 0.002$ & $0.0039 \pm 0.0015$ & 3.29 & 1.43 & 0.52 \\
\hline 355 & $0.022 \pm 0.003$ & $0.013 \pm 0.003$ & $0.0037 \pm 0.0032$ & 2.72 & 1.76 & 0.57 \\
\hline
\end{tabular}

${ }^{\mathrm{a}}$ Organisms fed YCT twice per week.

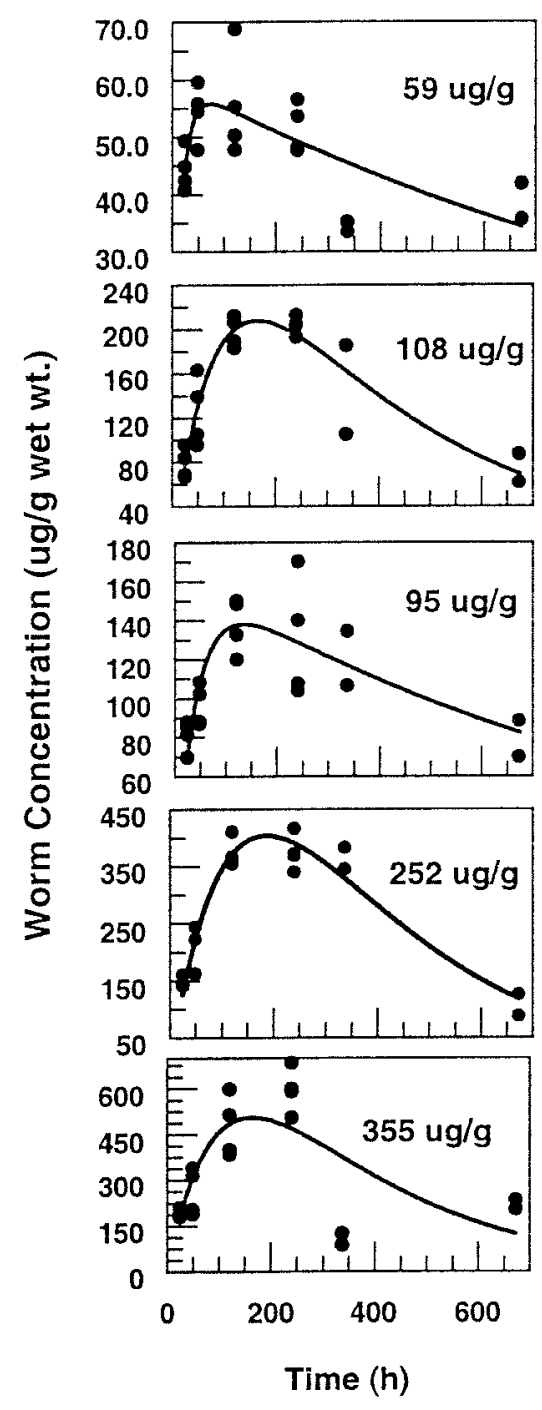

Fig. 2. Toxicokinetics of Lumbriculus variegatus over 28 days. The line indicates the fit of the toxicokinetics model to the data

The bioaccumulation factor (BAF, concentration in the organisms on a wet-weight basis divided by the concentration in sediment on a dry-weight basis) calculated as $k_{s} / k_{e}$ generally increased from 1.0 to 3.3 across treatments, reflecting primarily the decline in the elimination rate constant with increasing treatment concentration (Table 3). The values determined from

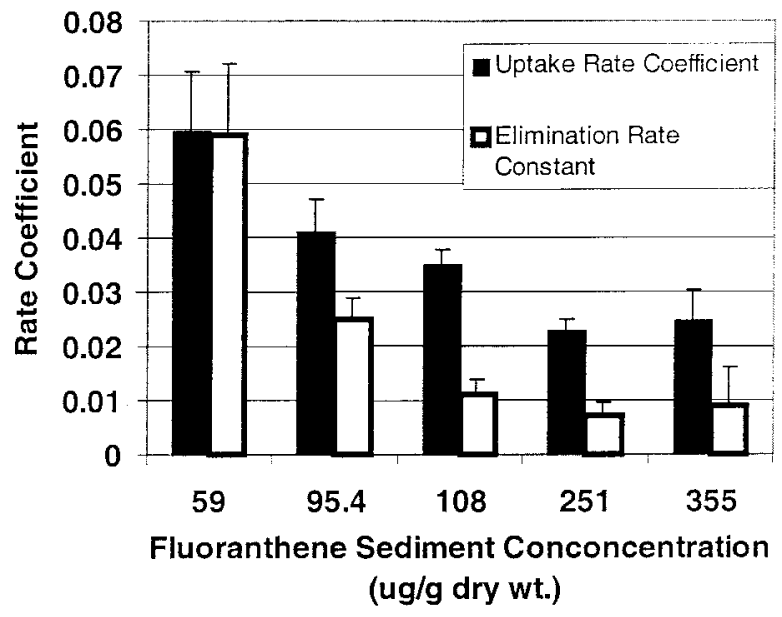

Fig. 3. Change in the uptake and elimination rate coefficients with increasing fluoranthene sediment concentration. The uptake rate coefficient has units of $\mathrm{g}$ dry sediment $\mathrm{g}^{-1}$ wet wt. worm $\mathrm{h}^{-1}$ and the elimination rate constant had units of $\mathrm{h}^{-1}$

the kinetics are generally larger than those measured at day 10 $(1.5 \pm 0.4)$ and much larger than the 28-day BAF $(0.74 \pm$ 0.23). Except for the $59 \mu \mathrm{g} \mathrm{g}^{-1}$ treatment, where the BAF was similar between the 10-day measured value and that determined from the kinetics. At the higher treatments without feeding, the values estimated from the kinetics were larger, suggesting that the oligochaetes do not attain steady-state concentrations.

The feeding of YCT to the worms was done to simulate the situation where fresh food particles float down from upstream and provide additional food. Adding fresh food resulted in both faster uptake and elimination of fluoranthene compared to the similar treatment without added food. Elimination was significantly greater in the presence of food, while the uptake was not. Thus the resultant BAF was smaller in the presence of food because of the greater elimination rate (Table 3 ).

\section{Discussion}

\section{Reproduction and Growth}

Reproduction was only statistically greater than the control in the 59 and $95 \mu \mathrm{g} \mathrm{g}^{-1}$ treatments when expressed as increases 


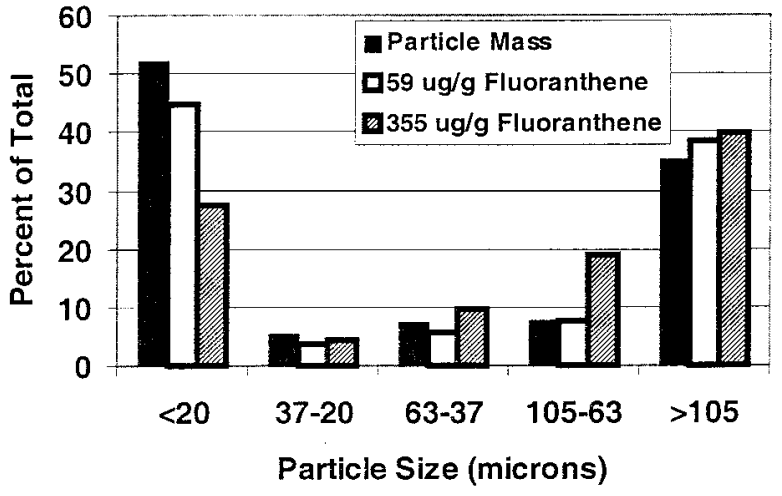

Fig. 4. The distribution of particle mass compared to the distribution of fluoranthene at 59 and $355 \mu \mathrm{g} \mathrm{g}^{-1}$ on various size particles $(\mathrm{n}=1)$. The accountability for fluoranthene radioactivity was $75 \%$ at $59 \mu \mathrm{g}$ $\mathrm{g}^{-1}$ and $70 \%$ at $355 \mu \mathrm{g} \mathrm{g}^{-1}$

in numbers of worms in the cells at 28 days. At $59 \mu \mathrm{g} \mathrm{g}^{-1}$ fluoranthene in sediment, the worms had body residues $(0.19 \pm$ $\left.0.02 \mathrm{mmol} \mathrm{kg}^{-1}\right)$ that were below concentrations of DDE and PCB congeners $\left(0.34-0.56 \mathrm{mmol} \mathrm{kg}^{-1}\right)$ delivered through contaminated food that had previously been demonstrated to produce reductions in reproduction (Fisher et al. 1999). However, there was no expectation of an increase relative to the controls. The mechanism for such an increase is unknown, although compensation to low-level stress often leads to apparent positive outcomes through hormesis. At the next higher treatment, $108 \mu \mathrm{g} \mathrm{g}^{-1}$, the number of worms declined relative to the 59 $\mu \mathrm{g} \mathrm{g}^{-1}$ treatment to a level similar to the control though greater than the number of worms added to the cells. Thus the apparent stimulation was overcome by the fluoranthene. The worms at this treatment had body residues of $0.53 \mathrm{mmol} \mathrm{kg}^{-1}$ (Table 1). These body residues are similar to those that produced reduced numbers of worms with exposures to DDE and PCB congeners (Fisher et al. 1999). However, these levels were not sufficient to reduce the numbers of worms below that of the controls. When the worms were exposed to $95 \mu \mathrm{g} \mathrm{g}^{-1}$ and fed, the number of worms increased substantially, apparently overcoming the impact of the fluoranthene. The worms in these expo-

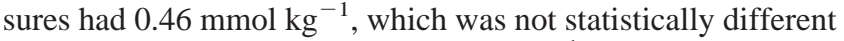
from that of worms exposed to $108 \mu \mathrm{g} \mathrm{g}^{-1}$ fluoranthene. Thus the addition of food was sufficient to overcome the fluoranthene stress comparing the 95 and $108 \mu \mathrm{g} \mathrm{g}^{-1}$ treatments. It was not possible to extend an analysis of the reproduction to the higher treatments because of the aeration problem. However, it appears that the PCB congeners and DDE are more toxic to the reproduction of $L$. variegatus than is fluoranthene because at similar or lower body residues the chlorinated compounds reduced the number of worms relative to controls, whereas fluoranthene did not.

Because L. variegatus reproduces by fission, another measure of health is the overall biomass in the cells. Despite the increase in the number of worms at the $59 \mu \mathrm{g} \mathrm{g}^{-1}$ treatment, the total mass of worms was not different from that of the controls. The only change in biomass was in the cells where the organisms were fed. In this case, the total biomass as well as the number of worms was significantly greater than the controls. Thus nutritional status can affect the outcome and inter- pretation of bioassays. The absence of a control with feeding and no fluoranthene precludes determining whether the $95 \mu \mathrm{g}$ $\mathrm{g}^{-1}$ treatment reflected an impact of fluoranthene with an added food ration. Thus the only comparison that can be made is relative to the $108 \mu \mathrm{g} \mathrm{g}^{-1}$ treatment, which does demonstrate that added food can alter the impact of fluoranthene at these exposure concentrations. The data on the total biomass also supports the finding that fluoranthene is less toxic to L. variegatus than are the PCB congeners and DDE. The body residue levels found in the fluoranthene experiment were equal or greater than those required to produce reductions in biomass by the chlorinated hydrocarbons (Fisher et al. 1999), and no reductions were evident for fluoranthene. Thus it may be that the chlorinated compounds act by a mechanism other than narcosis when affecting the reproduction and growth of $L$. variegatus. However, more work in this area is needed to develop such mechanistic understandings.

\section{Reworking Rates}

The increasing biological burial rate $\left(W_{b}\right)$ with increasing treatment concentration signifies an increase in ingestion rate with increasing fluoranthene exposure. The mechanism for burial is though the conveyor belt actions of the worms feeding at depth and depositing fecal material on the surface. Thus particles are removed at depth below the ${ }^{137} \mathrm{Cs}$ marker layer, causing the marker layer to move downward and be buried with the newly deposited fecal material. The reduced burial rate when the organisms were fed YCT was likely due to the tendency of the worms to stay near the surface to ingest the more nutritious material. This was confirmed by the extremely rapid biological diffusion rate for the organisms. When presented with fresh food, the worms do not tend to search at depth for nutrition.

The increasing biological burial rate with increasing fluoranthene concentration was not expected. This stimulation was observed at the lowest treatment concentration, corresponding to a body residue of $0.19 \mathrm{mmol} \mathrm{kg}^{-1}$ at 28 days. Thus the low body residue produced stimulation in both the burial rate and reproduction. The brief aeration problem at the end of the study resulted in having to use estimated values for the worm biomass at the end of the study to calculate biological burial rates for the two highest exposure concentrations. The assumption of $90 \%$ survival based on the number found in the kinetics beakers is likely a slight overestimate because only a few worms had departed the cells. Thus, the high biological burial rates would have been larger if a smaller mass of worms had existed in the cells. The rates are likely conservative. Previous studies demonstrated reduced biological burial with increasing exposure to contaminants. For the oligochaetes Stylodrilius heringianus and Limnodrilius hofmeisteri, the biological burial rate was similar or lower than controls with increasing sediment concentrations of endrin in sediment (Keilty et al. 1988a, 1988b). Such reductions have also been observed with a marine polychaete, Heteromastus filiformis, exposed to DDT (Mulsow and Landrum 1995). Thus, the increase in apparent feeding rate was not expected. Such increases in feeding rate have been speculated as a response to PAH exposures for other organisms. Diporeia spp. were assumed to increase feeding rate with increased exposure to pyrene based on the increases in the accumulation rate (Landrum et al. 1994). 
The difference in the response of the various worms to the chlorinated hydrocarbon pesticides as compared to fluoranthene may be the result of differences in the mechanism of toxic action. Both of the chlorinated hydrocarbon compounds are known neurotoxins, whereas fluoranthene is expected to act by narcosis for this organism. The assumption of baseline narcosis for the exposure of $L$. variegatus was reasonable because $L$. variegatus does not readily biotransform PAH (Kukkonen and Landrum 1994), and the exposure was performed in the presence of light with wavelength $>500 \mathrm{~nm}$ so that photo-induced toxicity should not have been important.

\section{Kinetics and Bioaccumulation}

Our original hypothesis was that ingestion processes would dominate both the uptake and elimination such that both the rates would increase with increasing biological burial rate $\left(W_{b}\right)$. Previous work had demonstrated that $61 \%$ of the accumulation of pyrene, a compound of similar $\log K_{\text {ow }}$ to fluoranthene, was due to ingestion (Leppänen and Kukkonen 1998). Also, the ingestion rate was thought to dominate the elimination process (Kukkonen and Landrum 1994). Thus, one of the important findings in this work is the disconnect between the biological burial rate, which is a function of the feeding rate of the organism, and the toxicokinetic rate coefficients. The biological burial rate increases with increasing fluoranthene concentration in sediment (Figure 1), and the toxicokinetic processes both uptake and elimination decline with increasing fluoranthene concentration (Figure 3). Benthic invertebrates may potentially accumulate contaminants from three sources: overlying water, ingested food, and interstitial water. The accumulation from pore water is thought to be kinetically limited by the desorption rate from sediment particles and the diffusion rate within sediments (Landrum and Robbins 1990). When accumulation of PAH was modeled for Diporeia spp., the accumulation of pyrene, a contaminant of similar $\log K_{\mathrm{ow}}$ to fluoranthene, occurred approximately $76 \%$ through the pore water based on the best available data on desorption rate (Landrum and Robbins 1990). Recent work has demonstrated that bioaccumulation is directly proportional to the rapidly desorbable fraction of the contaminant in sediment for tubificids (Kraaij et al. 2001). In addition, the accumulation kinetics were recently shown to be directly proportional to the flux of contaminant (desorption rate times fraction of rapidly desorbable compound) off sediment particles when the contaminants were at trace concentrations (Kukkonen and Landrum 2001). Finally, the half-life of desorption, determined from the maximum desorption rate, for the rapidly desorbable pool is short in the range of $2-5 \mathrm{~h}$ for pyrene from seven different sediments at low sediment concentrations, and the fraction of pyrene in this rapidly desorbable pool is between 19 and $54 \%$ of the total compound (unpublished data). However, based on the $\lambda$ values, the change in the bioavailable fraction, half-life $177-866 \mathrm{~h}$, is substantially slower than the maximum desorption rate measured in sediment. Still, the preponderance of the data suggest that the uptake kinetics observed for L. variegatus are likely dominated by the fluoranthene desorption rate from sediment although accumulation from ingestion is expected to contribute to the accumulation process. This hypothesis is the only de- fensible mechanism that supports a disconnect between the biological burial rate the uptake kinetics with increasing fluoranthene sediment concentration.

The elimination rate also declines as the biological burial rate increases, thus feeding rate does not appear to be a determining factor in the elimination rate process. This is consistent with recent work on the elimination of contaminants by the amphipod Diporeia spp. (Lotufo and Landrum 2001). The elimination was enhanced by feeding only when the compound was highly sorbed, such as for $\mathrm{BaP}$, but was not a factor for compounds like pyrene, which has a similar $\log K_{\mathrm{ow}}$ to fluoranthene. Rather, the loss to the water with sorption to particles seemed to dominate the process. As a result, elimination may be slower at higher concentration either because of approaching solubility limits in interstitial water or because of limits to the sorption capacity of the sediment, which might be reduced because at higher concentrations most of the available sites for sorption had been filled. Furthermore, this mechanism could account for some of the difference between the 95 and $108 \mu \mathrm{g} \mathrm{g}^{-1}$ exposures, with and without food addition, where the addition of fresh food could provide additional sorption capacity, helping enhance elimination. Thus, both the uptake and elimination are consistent with a strong aqueous connection as opposed to a particle feeding connection for fluoranthene.

The kinetics showed a decline in bioaccumulation after about 10 days (Figure 2), suggesting altered bioavailability to L. variegatus over the course of the exposure. A similar apparent decline in uptake after about 10 days has been observed in experimental systems for relatively rapidly desorbable compounds for Diporeia spp. (Landrum 1989) and L. variegatus (Kukkonen and Landrum 1994; Van Hoof et al. 2001), even when the contaminants were environmentally resident in the sediment (Harkey et al. 1995). Because this has been observed with well-equilibrated sediments, including this study, the phenomenon is not the result of the initial equilibration between the sediment and interstitial water. Based on the most recent desorption-bioavailability information, the likely cause of the decline in the bioaccumulation after 10 days is the decline exposure due to depletion of the rapidly desorbable pool within the biologically active region of the sediment. This type of bioaccumulation profile is not limited to laboratory studies but has also been observed in the field when naive organisms have been placed in in situ chambers exposed to sediments (Rowland and Burton 2000).

The change in the kinetics with increasing sediment contaminant concentrations has been previously observed for L. variegatus accumulation of pyrene from sediments (Kukkonen and Landrum 1994). The response relative to the exposure concentration resulted in declining $k_{s}$ values (Figure 5). Although the slopes were similar, the displacement of the intercepts of the two lines was thought to reflect the difference in bioavailability driven in part by differences in the organic carbon content of the sediments, $0.44 \%$ (Kukkonen and Landrum 1994) and 2\% for this study. However, normalization by organic carbon simply swaps the positions of the two lines, suggesting that the differences in bioavailability for compounds with the same log $K_{\text {ow }}$ is more complex than simple carbon normalization. The difference between compounds is now thought to result from the difference in desorption rates for the two PAHs from the two sediments.

If the toxicokinetics are driven by the sorption/desorption 


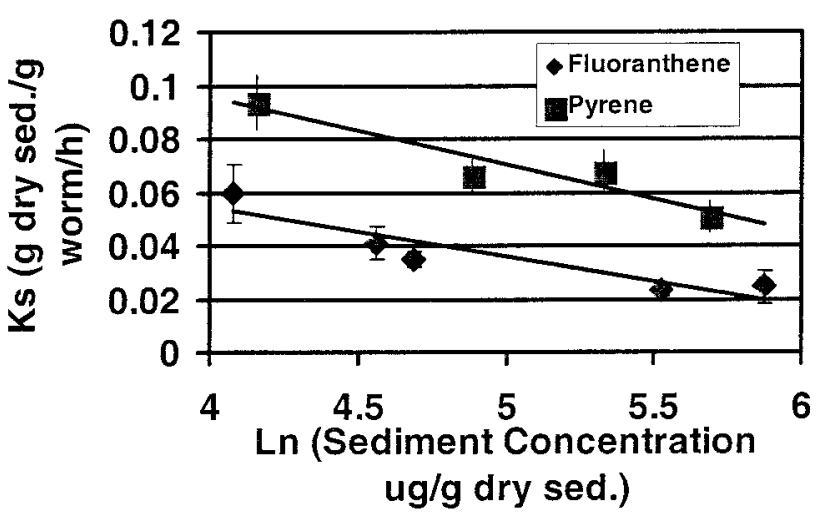

Fig. 5. Comparison of the uptake rate coefficients for fluoranthene and pyrene (Kukkonen and Landrum 1994) as a function of sediment concentration

processes as suggested above, then changes in contaminant concentrations apparently affect those processes. One factor that supports differences in the interaction of contaminants as the concentration changes is the apparent differences in distribution of fluoranthene relative to organic carbon with increasing fluoranthene concentration (Figure 4). Differences in the distribution of pyrene with increasing sediment concentration were also observed (Landrum and Kukkonen 1994). However, in the case of pyrene the fraction on the very finest particles increased at higher concentrations, whereas for fluoranthene the distribution tended toward larger particles with increasing concentration. The mechanism for interpreting the relative distribution of the contaminant within the sediment is an area that requires additional study.

The bioaccumulation potential determined by the ratio of $k_{s} / k_{e}$ were always greater than that measured (Table 3 ). The measured BAF in the 59 and $95 \mu \mathrm{g} \mathrm{g}^{-1}$ exposure concentrations at 10 days approached the theoretical steady-state values predicted from the toxicokinetics. This was apparently driven by the relatively smaller $\lambda$ values, indicating that the bioavailable fraction remained larger, and the larger $k_{e}$ values, allowing steady state to take place in a shorter time frame. The other treatment concentrations only attained about half the theoretical BAF at 10 days. In all cases, the change in bioavailability resulted in lower BAF values at 28 days. The BAF values found for fluoranthene were similar to those found for pyrene with L. variegatus (Kukkonen and Landrum 1994) with a somewhat lower organic carbon sediment. However, the lowest BAF was at the lowest pyrene concentation, and the higher $\mathrm{BAF}$ values for fluoranthene were at higher concentrations. The BAF values for fluoranthene were two to six times larger than that found for L. variegatus exposed to pyrene in a very fine 3.6\% organic carbon sediment (Leppänen and Kukkonen 1998). When normalized for organism lipid and organic carbon, the range of BSAF for pyrene and fluoranthene was 0.4 to 2.86 , with the lowest values found at high pyrene concentrations (this study; Leppänen and Kukkonen 1998; Kukkonen and Landrum 1994). In one study with L. variegatus exposed for 30 days, the concentration of PCBs in tissue was similar to that found in native oligochaetes (Ankley et al. 1992), suggesting that the 28-day value may be the most appropriate to compare to field conditions. However, the cyclic nature of bioaccumulation has recently been observed during in situ exposures of L. variegatus (Rowland and Burton 2000). This suggests that the temporal details of bioaccumulation may need to be better evaluated and that it may be important to understand the range of bioaccumulation as represented by the peaks and valleys in the observed accumulation.

\section{Summary}

The disconnect between the response of the biological burial rate and the toxicokinetic rate constants relative to the increasing fluoranthene sediment concentrations is one of the most important findings of this work. The biological burial rate reflects ingestion rate; thus, the toxicokinetics are apparently not closely tied to the extent of ingestion. This is supported by recent work that demonstrates that the desorption rate and uptake through interstitial water dominates for compounds with characteristics similar to fluoranthene and that elimination rates are driven by elimination into interstitial water and sorption to particles, rather than feeding behavior. The finding of increasing biological burial rate with increasing sediment fluoranthene concentration is different from the findings where oligochaetes were exposed to organochlorine compounds. It is not known why apparent stimulation occurs with fluoranthene. Stimulation by fluoranthene was also apparent in the reproduction response. The lowest internal concentrations required to produce such stimulation were in the range of $0.27-0.19 \mathrm{mmol}$ $\mathrm{kg}^{-1}$ (day 10 and day 28 concentrations). In terms of negative effects, L. variegatus seemed to be less responsive to fluoranthene than to DDE and PCB congeners (Fisher et al. 1999). The uptake coefficient for fluoranthene responded in a similar negative fashion with increasing treatment concentration as was previously observed for pyrene (Kukkonen and Landrum 1994). Finally, the bioaccumulation declined between day 10 and day 28. From previous work with PCBs, the 28-day concentrations may be more representative of the field. However, cyclic responses to bioaccumulation have been observed in the field as well as in the laboratory (Rowland and Burton 2000); therefore, more detailed comparative studies between the bioconcentration in the field and the laboratory need to be made.

Acknowledgment. This work was supported in part by the U.S. Environmental Protection Agency, grant R826200-01-0. We thank Dr. T. O. Tierman (Wright State University, Dayton, $\mathrm{OH}$ ) for the analysis of the sediment for the environmentally resident PAH content. The GLERL contribution number is 1219 .

\section{References}

Ankley GT, Schubauer-Berigan MK, Dierkes JR Jr (1991) Predicting the toxicity of bulk sediments to aquatic organisms with aqueous test fractions-pore water vs elutriate. Environ Toxicol Chem 10:1359-1366

Ankley GT, Cook PM, Carlson AR, Call DJ, Swenson JA, Corcoran HF, Hoke RA (1992) Bioaccumulation of PCBs from sediments by oligochaetes and fishes: comparison of laboratory and field studies. Can J Fish Aquat Sci 49:2080-2085

ASTM (2000) Standard test methods for measuring the toxicity of sedi- 
ment associated contaminants with freshwater invertebrates. E170695b, Water and Environmental Technology vol 11.05, American Society for Testing and Materials, West Conshohocken, PA

Bailey HC, Liu DHW (1980) Lumbriculus variegatus, a benthic oligochaete, as a bioassay organism. In: Eaton JC, Parrish PR, Hendricks AC (eds) Aquatic toxicology. ASTM STP 707, American Society for Testing and Materials, Philadelphia, pp 205-215

Boudreau BP (1986) Mathematics of tracer mixing in sediments: I. Spatially-dependent, diffusive mixing. Am J Sci 286:161-198

Crank J (1975) The mathematics of diffusion. Clarendon Press, Oxford University Press, $414 \mathrm{pp}$

Ditsworth GR, Schults DW, Jones JKP (1990) Preparation of benthic substrates for sediment toxicity testing. Environ Toxicol Chem 14:1551-1560

Drews CD (1997) Sublethal effects of environmental toxicants on oligochaete escape reflexes. Amer Zool 37:346-353

Fisher JB, Lick WJ, McCall PL, Robbins JA (1980) Vertical mixing of lake sediments by tubificid oligochaetes. J Geophys Res 85:39974006

Fisher SW, Chordas SW III, Landrum PF (1999) Lethal and sublethal body residues for PCB intoxication in the oligochaete, Lumbriculus variegatus. Aquat Toxicol 45:1115-1126

Gardner WS, Frez WA, Chichocki EA, Parrish CC (1985) Micromethod for lipid analysis in aquatic invertebrates. Limnol Oceaongr 30:1099-1105

Harkey GA, Van Hoof PL, Landrum PF (1995) Bioavailability of polycyclic aromatic hydrocarbons from a historically contaminated sediment core. Environ Toxicol Chem 14:1551-1560

Keilty TJ, Landrum PF (1990) Population-specific toxicity responses by the freshwater oligochaete, Stylodrilius heringianus, in natural Lake Michigan sediments. Environ Toxicol Chem 9:1147-1154

Keilty TJ, White DS, Landrum PF (1988a) Short-term lethality and sediment avoidance assays with endrin-contaminated sediment and two oligochaetes from Lake Michigan. Arch Environ Contam Toxicol 17:95-101

Keilty TJ, White DS, Landrum PF (1988b) Sublethal responses to endrin in sediment by Limnodirlus hoffmeisteri (tubificidae), and in mixed-culture with Stylodrilius heringianus (Lumbriculidae). Aquat Toxicol 13:227-250

Keilty TJ, White DS, Landrum PF (1988c) Sublethal responses to endrin in sediment by Stylodrilius heringianus (Lumbriculidae) as measured by a ${ }^{137}$ cesium marker layer technique. Aquat Toxicol 13:251-270

Kraaij RH, Ciarelli S, Tolls J, Kater BJ, Belfroid A (2001) Bioavailability of lab-contaminated and native polycyclic aromatic hydrocarbons to the amphipod, Corophium volutator, relates to chemical desorption. Environ Toxicol Chem 20:1716-1724

Krezoski JR, Robbins JA (1985) The vertical distribution of feeding and particle selective transport of ${ }^{137}$ cesium in lake sediments in the Lumbriculid oligochaetes. J Geophys Res 90:11999-12006

Kukkonen JV, Landrum PF (2001) Sediment characteristics other than TOC affect the desorption and bioavailability of non-polar chemicals. 11th Annual Meeting of the Society of Environmental Toxicology and Chemistry, Europe, Madrid, Spain, abstract 258

Kukkonen J, Landrum PF (1994) Toxicokinetics and toxicity of sediment-associated pyrene to Lumbriculus variegatus (Oligochaeta). Environ Toxicol Chem 13:1457-1468

Landrum PF (1989) Bioavailability and toxicokinetics of polycyclic aromatic hydrocarbons sorbed to sediments for the amphipod, Pontoporeia hoyi. Environ Sci Technol 23:588-595

Landrum PF, Robbins JA (1990) Bioavailability of sediment associated contaminants: a review and simulation model. In: Baudo R,
Giesy JP, Muntau H (eds) Sediments: chemistry and toxicity of in-place pollutants. Lewis Publishers, Chelsea, MI, pp 237-263

Landrum PF, Dupuis WS, Kukkonen J (1994) Toxicokinetics and toxicity of sediment-associated pyrene and phenanthrene in $\mathrm{Di}$ poreia spp.: examination of equilibrium-partitioning theory and residue-based effects for assessing hazard. Environ Toxicol Chem 13:1769-1780

Lawrence MAM, Davies NA, Edwards PA, Taylor MG, Simkiss K (2000) Can adsorption isotherms predict sediment bioavailability? Chemosphere 41:1091-1100

Leppänen MT, Kukkonen JVK (1998) Relative importance of ingested sediment and pore water as bioaccumulation routes for pyrene to oligochaete (Lumbriculus variegatus, Müller). Environ Sci Technol 32:1518-1525

Lotufo GR, Landrum PF (2001) The influence of sediment and feeding on the elimination of polycyclic aromatic hydrocarbons in the freshwater amphipod, Diporeia spp. Aquat Toxicol in press

McCall PL, Tevesz MJS (1982) The effects of benthos on physical properties of freshwater sediments. In: McCall PL, Tevesz MJS (eds) Animal sediment relations. Plenum, New York, p 336

McCarty LS, Mackay D (1993) Enhancing ecotoxicological modeling and assessment: body residue and modes of toxic action. Environ Sci Technol 27:1719-1728

Monson PD, Ankley GT, Kosian PA (1995) Phototoxic response of Lumbriculus variegatus to sediments contaminated by polycyclic aromatic hydrocarbons. Environ Toxicol Chem 14:891-894

Mount DR, Dawson TD, Burkhard LP (1999) Implications of gut purging for tissue residues determined in bioaccumulation testing of sediment with Lumbriculus variegatus. Environ Toxicol Chem 18:1244-1249

Mulsow SG, Landrum PF (1995) Bioaccumulation of DDT in a marine polychaete, the conveyor-bent deposit feeder Heteromastus filiformis (Claparede). Chemosphere 31:3141-3152

Reynoldson TB, Thompson SP, Bamsey JL (1991) A sediment bioassay using the tubificid ologichaete, Tubifex tubifex. Environ Toxicol Chem 10:1061-1072

Robbins JA (1986) A model for particle-selective transort of tracers in sediments with conveyor-belt deposit feeders. J Geophys Res 91:8542-8558

Robbins JA, McCall PL, Fisher JB, Krezoski JR (1979) Effect of deposit feeders on migrations of ${ }^{137} \mathrm{Cs}$ in lake sediments. Earth Planet Sci Lett 42:277-287

Rowland CD, Burton GA Jr (2000) In situ bioaccumulation of sediment associated PAHs and PCBs in the freshwater oligochaete, Lumbriculus variegatus and amphipod, Hyalella azteca. Society of Environmental Toxicology and Chemistry, 21st Annual Meeting, Nashville, TN, abstract PTA065

US EPA (1993) Methods for measuring the acute toxicity of effluents and receiving waters to freshwater and marine organisms, 4th ed. EPA/600/4-90/027F, US Environmental Protection Agency, Washington, DC

US EPA (2000) Methods for measuring the toxicity and bioaccumulation of sediment-associated contaminants with freshwater invertebrates. US Environmental Protection Agency. EPA/600/R-99/ 064. Washington. DC

Van Handel E (1985) Rapid determination of total lipids in mosquitos. J Am Mosq Control Assoc 1:302-304

Van Hoof PL, Kukkonen JVK, Landrum PF (2001) Impact of sediment manipulation on the bioaccumulation of PAHs from fieldcontaminated and laboratory-dosed sediments by an oligochaete. Environ Toxicol Chem 20:1752-1761 